\title{
The clinical value of the quantitative detection of four cancer-testis antigen genes in multiple myeloma
}

\author{
Yao Zhang, Li Bao, Jin Lu, Kai-Yan Liu, Jin-Lan Li, Ya-Zhen Qin, Huan Chen, Ling-Di Li, Yuan Kong, Hong-Xia Shi, \\ Yue-Yun Lai, Yan-Rong Liu, Bin Jiang, Shan-Shan Chen, Xiao-Jun Huang ${ }^{*}$ and Guo-Rui Ruan*
}

\begin{abstract}
Background: Cancer-testis (CT) antigen genes might promote the progression of multiple myeloma (MM). CT antigens may act as diagnostic and prognostic markers in $\mathrm{MM}$, but their expression levels and clinical implications in this disease are not fully understood. This study measured the expression levels of four $C T$ antigen genes in Chinese patients with MM and explored their clinical implications.

Methods: Real-time quantitative polymerase chain reaction (qPCR) was used to quantify the expression of MAGE-C1/CT7, MAGE-A3, MAGE-C2/CT10 and SSX-2 mRNA in 256 bone marrow samples from 144 MM patients.

Results: In the newly diagnosed patients, the positive expression rates were $88.5 \%$ for MAGE-C1/CT7, $82.1 \%$ for MAGE-C2/CT10, 76.9\% for MAGE-A3 and 25.6\% for SSX-2. The expression levels and the number of co-expressed CT antigens correlated significantly with several clinical indicators, including the percentage of plasma cells infiltrating the bone marrow, abnormal chromosome karyotypes and the clinical course.
\end{abstract}

Conclusion: MAGE-C1/CT7, MAGE-A3, MAGE-C2/CT10 and SSX-2 expression levels provide potentially effective clinical indicators for the auxiliary diagnosis and monitoring of treatment efficacy in MM.

Keywords: Cancer-testis antigen gene, Multiple myeloma, Real-time quantitative polymerase chain reaction

\section{Background}

Multiple myeloma (MM) is the second most common hematological cancer but the search for useful molecular markers in patients with MM has been highly challenging. The cancer-testis (CT) antigens are normally expressed in the testicles and trophoblastic cells of the ovary, and are also detected in some malignant tumors, such as MM and gastrointestinal stromal tumors [1-6]. CT antigens are capable of evoking spontaneous humoral and T-cell mediated immune responses and, due to their tumor-specific expression pattern and immunogenicity, $\mathrm{CT}$ antigens are considered as diagnostic tumor markers and potential targets for immunotherapy [7]. In addition, CT antigens are correlated with prognosis in pharyngeal cancer and non-small cell lung cancer $[8,9]$.

\footnotetext{
* Correspondence: xjhrm@medmail.com.cn; ruanguorui@pkuph.edu.cn Peking University People's Hospital and Institute of Hematology, Beijing Key Laboratory of Hematopoietic Stem Cell Transplantation, No.11 Xi-Zhi-Men
} South Street, 100044 Beijing, China
Although recent studies have shown that $\mathrm{CT}$ antigens are widely expressed at the mRNA and protein levels in MM patients [2], and are correlated with clinical outcomes and shorter survival durations [1,10-12], the patterns of expression and clinical implications of CT antigens have not been fully characterized. Additional data on the expression levels of CT antigens in MM may provide useful information to complement recent developments in diagnostic criteria and prognostic factors, and accelerate the development of effective individualized clinical treatment strategies for MM patients.

This study aimed to measure the expression levels of four CT antigen genes, MAGE-C1/CT7, MAGE-A3, MAGE-C2/CT10 and SSX-2, in samples of bone marrow from Chinese patients with MM using real-time quantitative PCR (qPCR), and to explore the clinical implications of $\mathrm{CT}$ antigen gene expression levels. The results of this study strongly suggested that MAGE-C1/CT7, MAGE-A3 and MAGE-C2/CT10 expression levels could 
act as clinical indicators for the auxiliary diagnosis and monitoring of treatment efficacy in MM.

\section{Results}

The expression frequency of the four CT antigen genes in multiple myeloma

In the newly diagnosed patients, $92.3 \%$ (72/78) of specimens expressed at least one of the four CT antigen genes. The rank of the positive expression rate in the newly diagnosed MM patients was MAGE-C1/CT7 $(88.5 \%, 69 / 78)>$ MAGE-C2/CT10 $(82.1 \%, 64 / 78)>$ MAGEA3 $(76.9 \%, 60 / 78)>$ SSX-2 $(25.6 \%, 20 / 78)$. When the samples of patients who responded to treatment (complete response, $\mathrm{CR}$ or partial response, $\mathrm{PR}$ ) were included, the percentage that expressed MAGE-C1/CT7, MAGE-A3, MAGE-C2/CT10 or SSX-2 was reduced to $67.3 \%$ (76/113), $45.1 \%$ (51/113), $46.0 \%(52 / 113)$ and $10.6 \%$ (12/113), respectively ( $\mathrm{p}<0.05$ for all). In non-responding patients, the rates of positive expression of the four genes increased significantly to $81.1 \%$ (43/53), $79.2 \%$ (42/53), $81.1 \%$ (43/53) and $32.1 \%$ (17/53), respectively (Table 1 ). All samples derived from the 22 healthy stem cell transplantation donors were negative for all four CT antigens.

The expression frequency of all four CT antigen genes was significantly higher in patients with BM plasma cell infiltration ( $\geq 10 \%$ vs. $<10 \%$ ). Additionally, MAGE-A3 was expressed at a higher rate in patients with a $\beta 2$ microglobulin level $\geq 3.5 \mathrm{mg} / \mathrm{L}$ compared to $<3.5 \mathrm{mg} / \mathrm{L}$ ( $80.7 \%$ vs. $59.5 \%, \mathrm{p}=0.01)$. MAGE-A3 was also increased with ISS staging (I: $57.1 \%$ vs. II: $66.7 \%$ vs. III: $85.2 \%, p=0.02$ ) (Table 2). No significant association could be found between the expression frequency of all four $\mathrm{CT}$ antigen genes and age, sex, albumin or calcium in serum.

\section{Co-expression patterns of $\mathrm{CT}$ antigen genes in multiple myeloma}

The co-expressed numbers of CT antigen genes of patients in remission decreased compared to those of untreated patients, non-responders to treatment, or relapsed patients (Table 1), which indicated that the co-expression of CT antigens was related to disease status.

We then analyzed the relationship between $\mathrm{CT}$ antigen expression and the clinical indices of MM. There was a moderate positive correlation between the co-expression of $\mathrm{CT}$ antigens and the percentage of $\mathrm{BM}$ plasma cell infiltration $(\mathrm{r}=0.51, \mathrm{n}=244, \mathrm{p}<0.01)$. The co-expression of $\mathrm{CT}$ antigens was marginally correlated with the percentage of del(13q14) positive cells $(r=0.44, n=30$, $\mathrm{p}=0.01)$, the percentage of $\operatorname{del}(13 \mathrm{q} 14.3)$ positive cells $(\mathrm{r}=0.42, \mathrm{n}=26, \mathrm{p}=0.02), \beta 2$-microglobulin levels $(\mathrm{r}=0.27$, $\mathrm{n}=178, \mathrm{p}<0.01)$, paraprotein levels $(\mathrm{r}=0.16, \mathrm{n}=164$, $\mathrm{p}<0.05)$, urinary free light chain levels $(\mathrm{r}=0.21, \mathrm{n}=126$, $\mathrm{p}=0.02)$, serum calcium levels $(\mathrm{r}=0.19, \mathrm{n}=199, \mathrm{p}<0.01)$, and blood sedimentation rates (ESR; $r=0.30, n=145$, $\mathrm{p}<0.01)$. CT antigens were negatively correlated with hemoglobin levels (Hb: $r=-0.24, n=205, p<0.01$ ).

\section{$\mathrm{CT}$ antigen expression levels correlate with the} percentage of plasma cells in bone marrow samples

The levels of CT antigen expression were detected by qPCR assays. The results showed that the percentages of BM plasma cell infiltration in 244 samples were positively correlated with expression levels of MAGE-C1/ CT7 $(r=0.50)$, MAGE-A3 $(r=0.51)$, MAGE-C2/CT10 $(\mathrm{r}=0.56)$ and SSX-2 $(\mathrm{r}=0.23)$, respectively (all $\mathrm{p}<0.01)$. Additionally, flow cytometry was used in 150 patients to detect the proportion of abnormal plasma cells. The expression levels of MAGE-C1/CT7 $(r=0.43)$, MAGE-

Table 1 The percentage of patients with positive expression and co-expression of the four CT antigens in patients with multiple myeloma

\begin{tabular}{|c|c|c|c|c|c|}
\hline \multirow[t]{2}{*}{ Samples groups } & \multicolumn{5}{|c|}{ Percentage of patients with positive expression } \\
\hline & MAGE-C1/CT7 & MAGE-A3 & MAGE-C2/CT10 & SSX-2 & $\geq 1 \mathrm{CT}$ antigen gene \\
\hline Newly diagnosed patients $(n=78)$ & $69(88.5 \%)$ & $60(76.9 \%)$ & $64(82.1 \%)$ & $20(25.6 \%)$ & $72(92.3 \%)$ \\
\hline In remission $(n=113)$ & $76(67.3 \%)$ & $51(45.1 \%)$ & $52(46.0 \%)$ & $12(10.6 \%)$ & $90(79.6 \%)$ \\
\hline Non-responders $(n=53)$ & $43(81.1 \%)$ & $42(79.2 \%)$ & $43(81.1 \%)$ & $17(32.1 \%)$ & $52(98.1 \%)$ \\
\hline Relapsed patients $(n=12)$ & $10(83.3 \%)$ & $9(75.0 \%)$ & $9(75.0 \%)$ & 7 (58.3\%) & $10(83.3 \%)$ \\
\hline \multirow[t]{3}{*}{${ }^{*} \mathrm{p}$-value } & $<0.01$ & $<0.01$ & $<0.01$ & $<0.01$ & $<0.01$ \\
\hline & \multicolumn{5}{|c|}{ Percentage of patients with positive co-expression of the four $\mathrm{CT}$ antigens } \\
\hline & 0 gene & 1 gene & 2 genes & 3 genes & 4 genes \\
\hline Newly diagnosed patients $(n=78)$ & $6(7.7 \%)$ & $4(5.1 \%)$ & $14(17.9 \%)$ & $35(44.9 \%)$ & $19(24.4 \%)$ \\
\hline In remission $(n=113)$ & $23(20.4 \%)$ & $32(28.3 \%)$ & $22(19.5 \%)$ & $27(23.9 \%)$ & $9(8.0 \%)$ \\
\hline Non-responders $(n=53)$ & $1(2.1 \%)$ & $9(16.7 \%)$ & $6(10.4 \%)$ & $23(43.8 \%)$ & $14(27.1 \%)$ \\
\hline Relapsed patients $(n=12)$ & $0(.0 \%)$ & $0(0 \%)$ & $2(20.0 \%)$ & $3(20.0 \%)$ & 7 (60.0\%) \\
\hline${ }^{*} p$-value & $<0.01$ & 0.01 & 0.42 & $<0.01$ & $<0.01$ \\
\hline
\end{tabular}

*p-values compared with newly diagnosed patients, patients in remission and those that were non-responders to treatment using the chi-square test. 
Table 2 Correlation of the clinicopathological characteristics of patients with MM with the expression of CT antigens

\begin{tabular}{|c|c|c|c|c|c|c|}
\hline Characteristics & & $\mathbf{n}$ & MAGE-C1 (\%) & MAGE-A3 (\%) & MAGE-C2 (\%) & SSX (\%) \\
\hline \multirow[t]{3}{*}{ Age (years) } & & & $p=0.36$ & $p=0.07$ & $p=0.35$ & $p=0.19$ \\
\hline & $<60$ & 84 & 81.0 & 64.3 & 71.4 & 29.8 \\
\hline & $\geq 60$ & 60 & 86.7 & 78.3 & 78.3 & 20.0 \\
\hline \multirow[t]{3}{*}{ Sex } & & & $p=0.94$ & $p=0.09$ & $p=0.57$ & $p=0.06$ \\
\hline & Male & 95 & 83.2 & 74.7 & 75.8 & 30.5 \\
\hline & Female & 49 & 83.7 & 61.2 & 71.4 & 16.3 \\
\hline \multirow[t]{5}{*}{ ISS staging } & & & $p=0.19$ & $p=0.02^{*}$ & $p=0.97$ & $p=0.12$ \\
\hline & । & 21 & 85.7 & 57.1 & 81.0 & 14.3 \\
\hline & $\|$ & 42 & 95.2 & 66.7 & 78.6 & 23.8 \\
\hline & III & 61 & 83.6 & 85.2 & 78.7 & 36.1 \\
\hline & Unknown & 20 & & & & \\
\hline \multirow[t]{4}{*}{ BM-infiltrating plasma cells } & & & $p<0.01^{*}$ & $p<0.01^{*}$ & $p<0.01^{*}$ & $p=0.03^{*}$ \\
\hline & $<10 \%$ & 64 & 73.4 & 50.0 & 54.7 & 17.2 \\
\hline & $\geq 10 \%$ & 78 & 91.0 & 87.2 & 91.0 & 33.3 \\
\hline & Unknown & 2 & & & & \\
\hline \multirow[t]{4}{*}{ ß2-microglobulin (mg/L) } & & & $p=0.19$ & $p=0.01^{*}$ & $p=0.12$ & $p=0.52$ \\
\hline & $<3.5$ & 37 & 75.7 & 59.5 & 67.6 & 24.3 \\
\hline & $\geq 3.5$ & 83 & 85.5 & 80.7 & 80.7 & 30.1 \\
\hline & Unknown & 24 & & & & \\
\hline
\end{tabular}

*A significant association as analyzed by the chi-square test.

A3 $(r=0.44)$, MAGE-C2/CT10 $(r=0.51)$ and SSX-2 $(\mathrm{r}=0.25)$ were all significantly correlated with the percentages of abnormal plasma cells ( $\mathrm{p}<0.01$ for all).

\section{CT antigen expression levels correlate with prognostic indices of multiple myeloma}

Levels of $\beta 2$-microglobulin, the most important and reliable prognostic factor in $\mathrm{MM}$, were correlated with MAGE-C1/CT7 $(r=0.21)$, MAGE-A3 ( $r=0.30)$, MAGEC2/CT10 $(r=0.25)$ and SSX-2 $(r=0.20)$ in 178 samples (all $\mathrm{p}<0.01$ ).

Multivariate Cox regression analysis was performed in 107 patients who had overall survival (OS) data to compare the prognostic values of $\beta 2$-microglobulin and the expression levels of the four genes. $\beta 2$-microglobulin $(\mathrm{p}=0.03)$, MAGE-C1/CT7 $(\mathrm{p}=0.04)$ could indicate poor OS rates with a significant prognostic value.

Furthermore, the expression levels of all four genes were also correlated with $\mathrm{Hb}$ levels $(\mathrm{r}=-0.17 \sim-0.31$, $\mathrm{n}=205, \mathrm{p}<0.01)$ and ESR $(\mathrm{r}=-0.23 \sim-0.31, \mathrm{n}=148$, $\mathrm{p}<0.01)$. Furthermore, ages was correlated with MAGEC1/CT7 $(r=0.24)$, MAGE-A3 $(r=0.29)$ and MAGE-C2/ CT10 expression $(r=0.25)$ in all patients $(\mathrm{p}<0.01$ for all $)$.

FISH analyses [including 1q21, del(13q14), del(13q14.3), $14 \mathrm{q} 32$ and $\operatorname{del}(17 \mathrm{p} 13)]$ were performed in some MM patients. These have been traditionally regarded as good prognostic markers of poorer outcome [13]. In our present study, MAGE-C1/CT7 was observed to be present more frequently in patients with del(13q14) $(\mathrm{p}=0.03)$. Additionally, there were higher expression levels of MAGE-C1/CT7 ( $<<0.01)$, MAGE-A3 ( $p=0.03)$ and MAGE-C2/CT10 $(\mathrm{p}=0.01)$ in patients with del (13q14), higher levels of MAGE-C2/CT10 in patients with $1 \mathrm{q} 21(\mathrm{p}=0.02)$ and MAGE-C1/CT7 in patients with del $(13 q 14.3)(p=0.04)$. However, there were no significant differences in the expression levels of the four CT antigen genes in patients either with or without the other cytogenetic abnormalities. The expression of MAGE-C1/CT7, MAGE-A3 and MAGE-C2/CT10 in patients with 1q21, del(13q14) and del(13q14.3) exhibited an increasing trend. Nevertheless, the expression of MAGE-C1/CT7, MAGEA3 and MAGE-C2/CT10 showed a decreasing trend in six patients with del(17p13) (Table 3), which requires further analysis. In addition, the expression levels of the four genes were significantly correlated with the percentage of del(13q14)-positive cells (MAGE-C1/CT7: $\mathrm{r}=0.37$, $\mathrm{p}=0.03$; MAGE-A3: $\mathrm{r}=0.34, \mathrm{p}<0.05$; MAGE-C2/CT10: $\mathrm{r}=0.59, \mathrm{p}<0.01$; and SSX-2: $\mathrm{r}=0.38, \mathrm{p}=0.03)$. The above findings indicated an association between cytogenetic abnormalities and three CT antigen genes.

\section{CT antigen expression levels correlate with the clinical course of multiple myeloma}

A longitudinal analysis was performed on $58 \mathrm{MM}$ patients during follow-up (median of three samples per patient; range: 2-9 samples). In order to facilitate the 
Table 3 Correlation of cytogenetic characteristics with CT antigen expression

\begin{tabular}{|c|c|c|c|c|c|c|}
\hline \multicolumn{2}{|l|}{ Characteristics } & $\mathrm{n}$ & $\begin{array}{c}\text { MAGE-C1 } \\
\text { Level (Positive percentage) }\end{array}$ & $\begin{array}{c}\text { MAGE-A3 } \\
\text { Level (Positive percentage) }\end{array}$ & $\begin{array}{c}\text { MAGE-C2 } \\
\text { Level (Positive percentage) }\end{array}$ & $\begin{array}{c}\text { SSX } \\
\text { Level (Positive percentage }\end{array}$ \\
\hline \multirow[t]{3}{*}{$\operatorname{Del}(13 q 14)$} & & & $p<0.01^{*}\left(0.03^{*}\right)$ & $p=0.03^{*}(0.10)$ & $p=0.01^{*}(0.20)$ & $p=0.25(0.15)$ \\
\hline & No & 44 & $214.94 \pm 830.59(72.7)$ & $8.26 \pm 27.53(65.9)$ & $2.50 \pm 8.54(70.5)$ & $0.06 \pm 0.22(15.9)$ \\
\hline & Yes & 30 & $443.20 \pm 838.11(93.3)$ & $36.85 \pm 127.23(83.3)$ & $23.77 \pm 98.61(83.3)$ & $0.02 \pm 0.06(30.0)$ \\
\hline \multirow[t]{3}{*}{$1 \mathrm{q} 21$} & & & $p=0.13(0.68)$ & $p=0.11(0.10)$ & $p=0.02^{*}(0.87)$ & $p=0.19(0.15)$ \\
\hline & No & 44 & $207.45 \pm 644.43(79.5)$ & $6.89 \pm 24.76(65.9)$ & $0.60 \pm 1.41(75.0)$ & $0.04 \pm 0.19(15.9)$ \\
\hline & Yes & 30 & $454.18 \pm 1050.80(83.3)$ & $38.86 \pm 127.58(83.3)$ & $26.56 \pm 98.45(76.7)$ & $0.04 \pm 0.14(30.0)$ \\
\hline \multirow[t]{3}{*}{ Del(17p13) } & & & $p=0.85(0.59)$ & $p=0.69(1.00)$ & $p=0.38(1.00)$ & $p=0.19(0.33)$ \\
\hline & No & 68 & $327.33 \pm 868.73(79.4)$ & $21.57 \pm 87.60(72.1)$ & $12.08 \pm 66.07(75.0)$ & $0.05 \pm 0.18(23.5)$ \\
\hline & Yes & 6 & $82.53 \pm 118.21(100.0)$ & $0.31 \pm 0.53(83.3)$ & $0.32 \pm 0.74(83.3)$ & $0.00 \pm 0.00(0)$ \\
\hline \multirow[t]{3}{*}{$14 q 32$} & & & $p=0.79(0.94)$ & $p=0.67(0.05)$ & $p=0.68(0.42)$ & $p=0.74(0.86)$ \\
\hline & No & 31 & $251.88 \pm 645.46(80.60)$ & $34.07 \pm 125.46(61.30)$ & $20.45 \pm 95.93(71.00)$ & $0.08 \pm 0.26(22.60)$ \\
\hline & Yes & 43 & $347.56 \pm 954.95(81.40)$ & $9.60 \pm 28.30(81.40)$ & $4.40 \pm 17.23(79.10)$ & $0.02 \pm 0.07(20.90)$ \\
\hline \multirow[t]{3}{*}{$\operatorname{Del}(13 q 14.3)$} & & & $p=0.04^{*}(0.07)$ & $p=0.18(0.27)$ & $p=0.21(0.45)$ & $p=0.22(0.16)$ \\
\hline & No & 48 & $233.06 \pm 815.48(75.00)$ & $7.71 \pm 26.40(68.80)$ & $2.62 \pm 8.19(72.90)$ & $0.05 \pm 0.21(16.70)$ \\
\hline & Yes & 26 & $444.86 \pm 870.69(92.30)$ & $42.25 \pm 136.20(80.80)$ & $26.83 \pm 105.86(80.80)$ & $0.02 \pm 0.06(30.80)$ \\
\hline
\end{tabular}

analysis, changes in the disease state from the clinical course of each patient were divided into three groups: improved (31 paired samples), stabilized (64 paired samples) and progressing disease (17 paired samples). The paired samples comprised samples before and after the change. Rank correlation analysis showed that the differences in the expression levels of MAGE-C1/CT7, MAGE-A3 and MAGE-C2/CT10 before and after the changes were consistent with the clinical course of individual patients (MAGE-C1/CT7: $r=0.36$; MAGE-A3: $\mathrm{r}=0.38$; MAGE-C2/CT10: $\mathrm{r}=0.28$; all $\mathrm{p}<0.01$ ).

Patients who failed to respond to chemotherapy showed consistently high expression levels of MAGE-C1/CT7, MAGE-A3 and MAGE-C2/CT10. The increased expression levels of the CT antigens exhibited a relapse or a progressive disease, and were correlated closely with clinical variables.

In contrast, patients who successfully responded to chemotherapy showed significant reductions in the expression levels of MAGE-C1/CT7, MAGE-A3 and MAGE-C2/ CT10. Additionally, their numbers of BM infiltrating plasma cells, paraprotein and $\beta 2$-microglobulin levels were also decreased. Patients who received auto-HSCT displayed a negative expression or reduced expression levels of MAGE-C1/CT7, MAGE-A3 and MAGE-C2/ CT10, which indicated a persistent and deeper level of remission. However, one patient who relapsed after auto-HSCT showed an increased expression level of MAGE-A3, and the other two patients who relapsed after auto-HSCT exhibited increased expression levels of all three genes (Figure 1).

\section{Discussion}

This study is the first quantitative analysis of the expression levels of four CT antigen genes, MAGE-C1/CT7, MAGE-A3, MAGE-C2/CT10 and SSX-2, in bone marrow cells from MM patients using $\mathrm{QPCR}$ to investigate the correlation between CT antigen expression levels and various clinical characteristics in MM. These results indicate that CT antigens are potentially effective molecular markers of MM, and have clinical implications for the auxiliary diagnosis and monitoring of treatment efficacy.

Our qPCR protocol provided a reliable and sensitive method for the quantification of MAGE-C1/CT7, MAGE-A3, MAGE-C2/CT10 and SSX-2 expression levels. The detection sensitivity was approximately $1-10$ copies for plasmid DNA standards and $10^{-4}-10^{-5}$ in bone marrow specimens which gave a high level of sensitivity and was less time-consuming than traditional RT-PCR [1] or immunohistochemical methods [14].

The four CT antigen genes were expressed at a high frequency in MM patients. MAGE-C1/CT7 was the most commonly expressed gene in newly diagnosed and relapsed patients, followed by the expression levels of MAGE-A3, MAGE-C2/CT10 and SSX-2. The positive expression rate of the four $\mathrm{CT}$ antigens was significantly lower in patients who responded to treatment, and the $\mathrm{CT}$ antigens were not detected in the bone marrow specimens of normal volunteers. These findings indicated that MAGE-C1/CT7, MAGE-A3, MAGE-C2/CT10 and SSX-2 were prominent MM-related tumor-specific genes, and could be used as potential molecular markers of MM. 


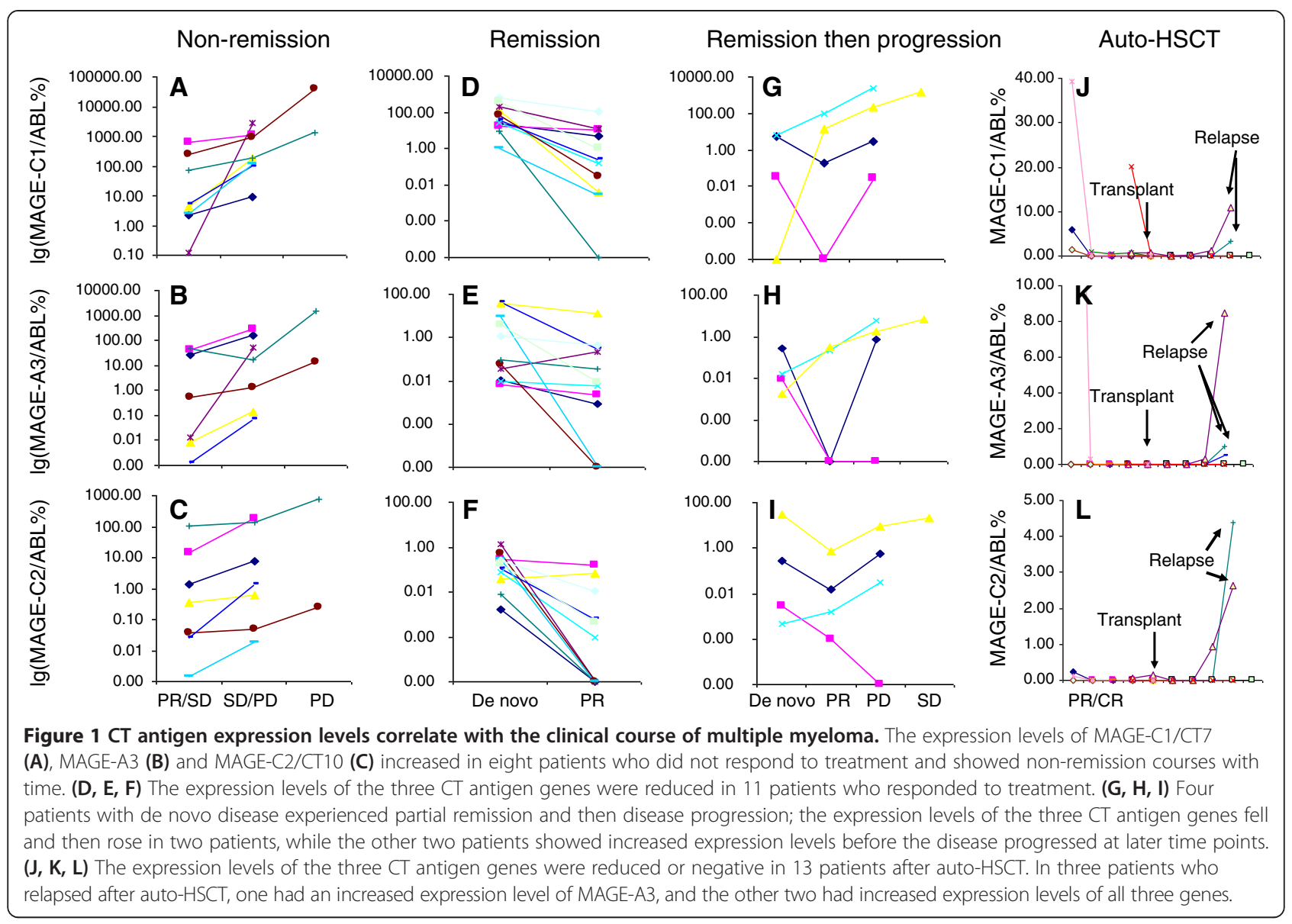

Further analysis of the clinical data demonstrated that both the number of co-expressed $\mathrm{CT}$ antigens and the expression levels of MAGE-C1/CT7, MAGE-A3, MAGEC2/CT10 and SSX-2 were associated with the percentage of plasma cells that infiltrated the bone marrow. This finding suggested that patients expressing multiple and/or high levels of $\mathrm{CT}$ antigens had a higher load of myeloma cells. Previous results had demonstrated that the MAGEC1/CT7 and MAGE-A3 were expressed in isolated plasma cells using anti-CD138-conjugated magnetic beads [15], and the expression levels of both genes were associated with the numbers of CD138-positive plasma cells.

In addition, the patterns of change observed in the expression of $\mathrm{CT}$ antigens were consistent with the clinical course of MM. Increasing CT antigen expression indicated relapsing or progressive disease, and reduced levels or negative $\mathrm{CT}$ antigen expression levels occurred during treatment response. Therefore, the CT antigen expression levels could reflect the clinical status of MM, and may have clinical value for the monitoring of disease progression and evaluating of treatment efficacy.

Finally, the prognostic ability of the four CT antigens in MM was analyzed. The expression levels of MAGEC1/CT7, MAGE-A3, MAGE-C2/CT10 and SSX-2 were correlated with prognostic factors for MM, including $\beta 2$ microglobulin, abnormal chromosome karyotypes, age and the hemoglobin level. It appeared that MAGE-C1/ CT7 had a similar prognostic value to $\beta 2$-microglobulin, which is currently the most valued prognostic indictor for MM. Accordingly, MAGE-C1/CT7 was identified as the leading candidate as a prognostic indictor compared to the other three genes. Chromosomal abnormalities, including 1q21, del(13q14) and del(13q14.3), were associated with poor survival rates and a more aggressive disease course [13]. In the present study, higher expression levels of MAGE-C1/CT7, MAGE-A3, MAGE-C2/ CT10 were found in patients with $\operatorname{del}(13 \mathrm{q} 14)$, higher levels of MAGE-C2/CT10 were found in patients with $1 \mathrm{q} 21$ and MAGE-C1/CT7 was more commonly found in patients with del(13q14.3), which indicated that the three genes had the same negative effect on prognosis. Del (17p13) was also found to be an important molecular cytogenetic marker for poor prognosis. The expression of MAGE-C1/CT7 has been reported to be more frequent in patients with $\operatorname{del}(17 \mathrm{p} 13)(\mathrm{p}=0.047)$ [16]. MAGE-C1/CT7, MAGE-A3 and MAGE-C2/CT10 showed a decreasing trend in six patients with del(17p13), but the correlation between CT antigen gene expression and del 
(17p13) require further validation in a large population of patients.

The correlations between MAGE-C1/CT7, MAGE-A3, MAGE-C2/CT10 or SSX-2 expression and clinical indicators in the present study suggest that each CT antigen has a unique role in MM. The expression of MAGE-C1/ CT7 was the most useful indictor in patients with MM, while MAGE-A3 and MAGE-C2/CT10 might confer an additive value for the prediction of disease complications and prognosis. A previous study showed that MAGE-A3 was also expressed in patients with MGUS and myeloma, which suggested that the expression of MAGE-A family members could be a common phenomenon or perhaps even an early event in the evolution of plasmacell diseases [15]. SSX-2 was expressed at very low levels in MM patients. Nevertheless, the positive expression of SSX-2 in patients with MM may still have a value for the diagnosis and prognosis of MM patients. It had been reported previously that SSX-2 levels were significantly associated with an adverse prognosis and reduced survival [17], and future studies will define the role of SSX-2 expression in MM pathogenesis.

\section{Conclusion}

MAGE-C1/CT7, MAGE-A3, MAGE-C2/CT10 and SSX-2 were found to be frequently expressed in MM patients. The positive expression of CT antigens, their co-expressed numbers, and the expression levels were significantly associated with recognized clinical indicators that reflect the severity of the disease, including BM plasma cells, $\beta 2$ microglobulin and abnormal chromosome karyotypes. The expression levels of MAGE-C1/CT7, MAGE-A3 and MAGE-C2/CT10 were also correlated with clinical course. The expression levels of the four CT genes could be potentially used as clinical indicators for the auxiliary diagnosis and monitoring of treatment efficacy in MM patients. To improve the diagnosis and treatment of MM patients, the roles of $\mathrm{CT}$ antigens in the development and progression of this disease await clarification.

\section{Methods}

\section{Patients}

Between November 2006 and December 2010, 144 MM patients were enrolled in this study; 78 (54.2\%) patients were newly diagnosed, $17(11.8 \%)$ had a complete response (CR), 24 (16.7\%) had a partial response (PR), five (3.5\%) had a progressive disease (PD), 10 (6.94\%) had stable disease (SD) and $10(6.94 \%)$ were from patients with relapsed disease. The median patient age was 58 years, and $66.0 \%$ of patients were male. The clinical data of all patients is showed in Table 1.

The most common isotype was IgGk 44 (30.6\%), 29 (20.1\%) were IgG $\lambda$, 14 (9.7\%) were IgAk, 18 (12.5\%) were $\operatorname{IgA} \lambda, 6(4.2 \%)$ were $\operatorname{IgD} \lambda, 18$ (12.5\%) were $\mathrm{k}$ light chain isotype, 11 (7.6\%) were $\lambda$ light chain isotype and four (2.8\%) patients had nonsecretory MM. Most patients after diagnosis accepted four cycles of induction treatments that included BD (consisting of intravenous bortezomib at 1.0 or $1.3 \mathrm{mg} / \mathrm{m}^{2}$ on days $1,4,8$, and $11,40 \mathrm{mg}$ dexamethasone on days 1 to 4 , followed by a 3-week rest period) or TD (thalidomide given orally at $200 \mathrm{mg} / \mathrm{d}$; and dexamethasone given orally at $40 \mathrm{mg}$ on days 1 to 4 , followed by a 4 -week rest period). The therapeutic response was assessed after induction treatments. If PR occurred, patients proceeded to autologous hematopoietic stem cell transplantation (auto-HSCT). Both transplanted and non-transplanted patients received maintenance therapy with thalidomide $(75-200 \mathrm{mg} / \mathrm{d})$ plus dexamethasone (20-40 mg/d) for 1 year. Diagnosis, staging and therapeutic effects were defined using widely used standard criteria [18,19]. Informed consent was obtained from all patients and 22 allogeneic stem cell transplantation donors prior to their enrollment in the study. The study design adhered to the principles of the Helsinki Declaration and was approved by the ethics committee of Peking University People's Hospital.

\section{Bone marrow samples and sample preparation}

Two-hundred and fifty-six BM samples were obtained from patients with MM during routine diagnostic procedures at the Peking University People's Hospital. Mononuclear cells were isolated from BM samples using standard Ficoll-Hypaque density gradient centrifugation. RNA was extracted from mononuclear cells using the TRIzol technique (Invitrogen, Carlsbad, CA, USA) according to the manufacturer's instructions. cDNA was synthesized as previously described [20].

\section{Real-time quantitative PCR}

The primers and probes were designed using Primer Express 2.0 software (Applied Biosystems, Foster City, California, USA) as follows: ABL (forward 5'-CCGCTGAC CATCAATAAGGAA-3', reverse 5' -GATGTAGTTGCTT GGGACCCA-3' and probe 5'-FAM-CCATTTTTGGTTT GGGCTTCACACCATT-TAMARA-3') [21], MAGE-C1/ CT7 (forward 5' -TTGTCTTCTGGGAACCTTGACTC-3', reverse $5^{\prime}$-TGAGGGACACATACATCCTAAAAGC-3' and probe $5^{\prime}$-FAM-ACTGCCTGGGCCTCCTCTGCTGT-BHQ3'), MAGE-A3 (forward 5'-GGTGAGGAGGCAAGGT TCTGA-3', reverse, 5'-GTGCTGACTCCTCTGCTCA AGAG-3' and probe, 5'-FAM-AGATCTGCCAGTGG GTCTCCATTGCC-BHQ-3'), MAGE-C2/CT10 (forward 5'-GTGTGAGGCACACAGCCTAAAG-3', reverse 5'-GG AGGCATGACGACTTCTTCA-3' and probe $5^{\prime}$-FAMAGGAGTCAAGGCCTGTTGGATCTCATCA-BHQ-3') and SSX-2 (forward 5' -TAACCGTGGGAATCAGGTT GA-3', reverse 5'-CCTCCGAATCATTTCCTTCCT-3' and probe $5^{\prime}$-FAM-CCGAAGATCATGCCCAAGAAGCC 
AG-BHQ-3'). The 10- $\mu$ l PCR reaction mixture contained $5 \mu \mathrm{l} 1 \times$ TaqMan $^{\oplus}$ Universal PCR Master Mix (Applied Biosystems, Foster City, California, USA), $400 \mathrm{nM}$ primers, $250 \mathrm{nM}$ fluorescent probes and 150-500 ng cDNA. PCR was performed using the ABI PRISM ${ }^{\circ} 7500$ FAST Sequence Detection System (Applied Biosystems) at $50^{\circ} \mathrm{C}$ for $2 \mathrm{~min}$ and $95^{\circ} \mathrm{C}$ for $10 \mathrm{~min}$, followed by 50 cycles at $95^{\circ} \mathrm{C}$ for $15 \mathrm{~s}$ and $60^{\circ} \mathrm{C}$ for $1 \mathrm{~min}$. The expression levels of the four CT antigen genes (MAGE-C1/CT7, MAGE-C2/ CT10, MAGE-A3 and SSX-2) were quantified by qPCR using the abelson $(A B L)$, glyceraldehyde-3-phosphate dehydrogenase (GAPDH), beta-glucuronidase (GUS) and $\beta 2$-microglobulin $(\beta 2 M)$ genes as internal control genes, respectively, as described previously $[21,22]$. On the basis of our previous study of the four control genes, $A B L$ was a more appropriate control gene in MM patients (Clinical and Experimental Medicine, accepted, DOI:10.1007/ s10238-013-0257-2, 2013). Therefore, the copy numbers of the four CT antigen genes and $A B L$ were calculated using the $C_{t}$ values on standard curves, and results were analyzed following the guidelines proposed by the European Study Group for qPCR [23].

Serial dilutions of the plasmids $\left(10^{6}, 10^{5}, 10^{4}, 10^{3}, 10^{2}\right.$, $10^{1}$ and $10^{\circ}$ copies) that expressed ABL and the four CT antigen genes were amplified by qPCR to construct standard curves for quantification, respectively. The plasmids were prepared as previously described ${ }^{18}$. A linear correlation was observed between the $C_{t}$ values and plasmid copy number, with a correlation coefficient of $>0.99$ for all curves. The standard curves revealed a similar efficiency of amplification for ABL, MAGE-C1/CT7, MAGE-A3, MAGE-C2/CT10 and SSX-2, with slopes of -3.22, -3.28, $-3.57,-3.43$ and -3.51 , respectively. As the amplification efficiency was similar for all genes, the CT antigens were quantified against the ABL standard curve in bone marrow specimens to decrease experimental error. For each measurement, the curve threshold amplification was set at 0.08 for $\mathrm{ABL}$ and the other three $\mathrm{CT}$ antigen genes. The detection sensitivity was approximately $1-10$ copies in the plasmid DNA standards and $10^{-4}-10^{-5}$ in CT antigenpositive bone marrow specimens.

\section{Flow cytometry}

Fresh BM samples were analyzed using standard flow cytometry using a four-color immunofluorescence technique as previously described [24]. BM samples were analyzed for the surface and cytoplasmic staining of CD19, CD38, CD45, CD56, CD117, CD138, $\mathrm{k}$ and $\lambda$, amongst others, to identify malignant plasma cells.

\section{Cytogenetics}

Cytogenetic FISH analyses were performed using standard methods [25]. The definition of a cytogenetic clone and the karyotype descriptions followed the International System for Human Cytogenetic Nomenclature.

\section{Statistical analysis}

All statistical analyses were performed using SPSS 13.0 (SPSS Inc., Chicago, IL, USA). Analysis of variance was used for continuous variables and $X^{2}$ tests were used for categorical variables. The correlation between the clinical indices and the expression level of the four CT antigen genes were analyzed using linear correlation analysis. Multivariate Cox regression analysis was performed to compare the prognostic value. Rank correlation analyses were used to assess the correlation between the clinical course and the expression levels of the CT antigen genes. P-values $<0.05$ was considered significant for all analyses.

\section{Competing interest}

The authors declare that they have no competing interest.

\section{Authors' contributions}

GRR and XJH designed the project, advised on the study and revised manuscript. YZ performed RQ-PCR experiment and all statistical analyses, contributed to the interpretation of the data and wrote the manuscript. $Y Z$, $L B, J L, K Y L, H C, Y K, H X S, B J$, and SSC fulfilled ethical authorizations, collected and stored clinical data. JLL, YZQ and LDL performed sample handling and storage. YRL and YYL contributed to flow cytometry and cytogenetics detection, respectively. All authors read and approved the final manuscript.

\section{Acknowledgments}

This study was supported by grants from the National Basic Research Program of China (Grant 2013CB733701), the Beijing Municipal Science and Technology Program (Grant Z111107067311070), the National Natural Science Foundation of China (Grant 81170484), and the Beijing Municipal Natural Science Foundation (Grant 7122199).

Received: 18 September 2013 Accepted: 20 December 2013 Published: 5 February 2014

\section{References}

1. Atanackovic D, Luetkens T, Hildebrandt Y, Arfsten J, Bartels K, Horn C, Stahl T, Cao Y, Zander AR, Bokemeyer C, Kröger N: Longitudinal analysis and prognostic effect of cancer-testis antigen expression in multiple myeloma. Clin Cancer Res 2009, 15(4):1343-1352.

2. Meklat F, Li Z, Wang Z, Zhang Y, Zhang J, Jewell A, Lim SH: Cancer-testis antigens in haematological malignancies. Br J Haematol 2007, 136(6):769-776.

3. Atanackovic D, Hildebrandt Y, Jadczak A, Cao Y, Luetkens T, Meyer S, Kobold S, Bartels K, Pabst C, Lajmi N, Gordic M, Stahl T, Zander AR, Bokemeyer C, Kröger $\mathrm{N}$ : Cancer-testis antigens MAGE-C1/CT7 and MAGE-A3 promote the survival of multiple myeloma cells. Haematologica 2010, 95(5):785-793.

4. Perez D, Herrmann $T$, Jungbluth AA, Samartzis P, Spagnoli G, Demartines N, Clavien PA, Marino S, Seifert B, Jaeger D: Cancer testis antigen expression in gastrointestinal stromal tumors: new markers for early recurrence. Int J Cancer 2008, 123:1551-1555.

5. Güre AO, Stockert E, Arden KC, Boyer AD, Viars CS, Scanlan MJ, Old LJ, Chen YT: CT10: A new cancer-testis (CT) antigen homologous to CT7 and the MAGE family, identified by refresentational-difference analysis. Int $J$ Cancer 2000, 85:726-732.

6. Jungbluth AA, Chen YT, Busam KJ, Coplan K, Kolb D, Iversen K, Williamson B, Van Landeghem FK, Stockert E, Old LJ: CT7 (MAGE-C1) antigen expression in normal and neoplastic tissues. Int J Cancer 2002, 99:839-845.

7. Atanackovic D, Arfsten J, Cao Y, Gnjatic S, Schnieders F, Bartels K, Schilling G, Faltz C, Wolschke C, Dierlamm J, Ritter G, Eiermann T, Hossfeld DK, Zander AR, Jungbluth AA, Old LJ, Bokemeyer C, Kröger N: Cancer-testis antigens are commonly expressed in multiple myeloma and induce systemic immunity following allogeneic stem cell transplantation. Blood 2007, 109:1103-1112. 
8. Pastorcic-Grgic M, Sarcevic B, Dosen D, Juretic A, Spagnoli GC, Grgic M: Prognostic value of MAGE-A and NY-ESO-1 expression in pharyngeal cancer. Head Neck 2010, 32:1178-1184.

9. Shigematsu Y, Hanagiri T, Shiota H, Kuroda K, Baba T, Mizukami M, So T, Ichiki Y, Yasuda M, So T, Takenoyama M, Yasumoto K: Clinical significance of cancer/testis antigens expression in patients with non-small cell lung cancer. Lung cancer 2010, 68:105-110.

10. Cumova J, Potacova A, Zdrahal Z, Hajek R: Proteomic Analysis in Multiple Myeloma Research. Mol Biotechnol 2011, 47:83-93.

11. Condomines M, Hose D, Raynaud P, Hundemer M, De Vos J, Baudard M, Moehler T, Pantesco V, Moos M, Schved JF, Rossi JF, Rème T, Goldschmidt $H$, Klein B: Cancer/testis genes in multiple myeloma: expression patterns and prognosis value determined by microarray analysis. J Immunol 2007 178:3307-3315.

12. Van Duin M, Broyl A, De Knegt Y, Goldschmidt H, Richardson PG, Hop WC, van der Holt B, Joseph-Pietras D, Mulligan G, Neuwirth R, Sahota SS, Sonneveld P: Cancer testis antigens in newly diagnosed and relapse multiple myeloma: prognostic markers and potential targets for immunotherapy. Haematologica 2011, 96(11):1662-1669.

13. Fonseca R, Bergsagel PL, Drach J, Shaughnessy J, Gutierrez N, Stewart AK, Morgan G, Van Ness B, Chesi M, Minvielle S, Neri A, Barlogie B, Kuehl WM, Liebisch P, Davies F, Chen-Kiang S, Durie BG, Carrasco R, Sezer O, Reiman T, Pilarski L, Avet-Loiseau H: International Myeloma Working Group molecular classification of multiple myeloma: spotlight review. Leukemia 2009, 23:2210-2221.

14. Riener MO, Wild PJ, Soll C, Knuth A, Jin B, Jungbluth A, Hellerbrand C, Clavien PA, Moch $\mathrm{H}$, Jochum W: Frequent expression of the novel cancer testis antigen MAGE-C2/CT-10 in hepatocellular carcinoma. Int $J$ Cancer 2009, 124:352-357.

15. Jungbluth AA, Ely S, DiLiberto M, Niesvizky R, Williamson B, Frosina D, Chen YT, Bhardwaj N, Chen-Kiang S, Old L, Cho HJ: The cancer-testis antigens CT7 (MAGE-C1) and MAGE-A3/6 are commonly expressed in multiple myeloma and correlate with plasma-cell proliferation. Blood 2005, 106(1):167-174.

16. Pabst C, Zustin J, Jacobsen F, Luetkens T, Kröger N, Schilling G, Bokemeyer C, Sauter G, Atanackovic D, Marx A: Expression and prognostic relevance of MAGE-C1/CT7 and MAGE-C2/CT10 in osteolytic lesions of patients with multiple myeloma. Exp Mol Pathol 2010, 89(2):175-181.

17. Taylor BJ, Reiman T, Pittman JA, Keats JJ, De Bruijn DR, Mant MJ, Belch AR, Pilarski LM: SSX cancer testis antigens are expressed in most multiple myeloma patients: co-expression of SSX1, 2, 4, and 5 correlates with adverse prognosis and high frequencies of SSX-positive PCs. I Immunother 2005, 28(6):564-575.

18. Greipp PR, San Miguel J, Durie BG, Crowley JJ, Barlogie B, Bladé J, Boccadoro M, Child JA, Avet-Loiseau H, Kyle RA, Lahuerta JJ, Ludwig H, Morgan G, Powles R, Shimizu K, Shustik C, Sonneveld P, Tosi P, Turesson I, Westin J: International Staging System for Multiple Myeloma. J Clin Oncol 2005, 15:3412-3420.

19. Durie BG, Harousseau JL, Miguel JS, Bladé J, Barlogie B, Anderson K, Gertz M, Dimopoulos M, Westin J, Sonneveld P, Ludwig H, Gahrton G, Beksac M, Crowley J, Belch A, Boccadaro M, Cavo M, Turesson I, Joshua D, Vesole D, Kyle R, Alexanian R, Tricot G, Attal M, Merlini G, Powles R, Richardson P, Shimizu K, Tosi P, Morgan G, Rajkumar SV: International uniform response criteria for multiple myeloma. Leukemia 2006, 20:1467-1473.

20. Ruan GR, Qin YZ, Chen SS, Li JL, Ma X, Chang Y, Wang YZ, Fu JY, Liu YR: Abnormal expression of the programmed cell death 5 gene in acute and chronic myeloid leukemia. Leuk Res 2006, 30(9):1159-1165.

21. Niu J, Li H, Zhang Y, Li J, Xie M, Li L, Qin X, Qin Y, Guo X, Jiang Q, Liu Y, Chen S, Huang X, Han W, Ruan G: Aberrant expression of CKLF-like MARVEL transmembrane member 5 (CMTM5) by promoter methylation in myeloid leukemia. Leuk Res 2011, 35:771-776.

22. Beillard $\mathrm{E}$, Pallisgaard $\mathrm{N}$, van der Velden $\mathrm{VH}$, Bi W, Dee $\mathrm{R}$, van der Schoot $\mathrm{E}$, Delabesse E, Macintyre E, Gottardi E, Saglio G, Watzinger F, Lion T, Van Dongen $\mathrm{J}$, Hokland P, Gabert J: Evaluation of candidate control genes for diagnosis and residual disease detection in leukemic patients using 'real-time' quantitative reverse-transcriptase polymerase chain reaction (RQ-PCR) - a Europe against cancer program. Leukemia 2003, 17:2474-2486.

23. van der Velden VH, Hochhaus A, Cazzaniga G, Szczepanski T, Gabert J, Van Dongen JJ: Detection of minimal residual disease in hematologic malignancies by real-time quantitative PCR: principles, approaches, and laboratory aspects. Leukemia 2003, 17:1013-1034.
24. Liu YR, Yu H, Chang Y, Chen SS: The application of 4-color fluorescence labeling antibodies and its significance in immunophenotyping for leukemia by flow cytometer. Zhong guo Shi Yan Xue Ye Xue Za Zhi 2003, 10:423-427.

25. Zhang Y, He Q, Huang XJ, Jiang H, Yang SM, Lu J, Qing YZ, Shi Y, Dang H, Qiu JY, Lu DP: Cytogenetic study on eosinophilia. Zhong guo Shi Yan Xue Ye Xue Za Zhi 2007, 15:454-457.

doi:10.1186/1476-4598-13-25

Cite this article as: Zhang et al:: The clinical value of the quantitative detection of four cancer-testis antigen genes in multiple myeloma. Molecular Cancer 2014 13:25.

\section{Submit your next manuscript to BioMed Central and take full advantage of:}

- Convenient online submission

- Thorough peer review

- No space constraints or color figure charges

- Immediate publication on acceptance

- Inclusion in PubMed, CAS, Scopus and Google Scholar

- Research which is freely available for redistribution

Submit your manuscript at www.biomedcentral.com/submit
C Biomed Central 